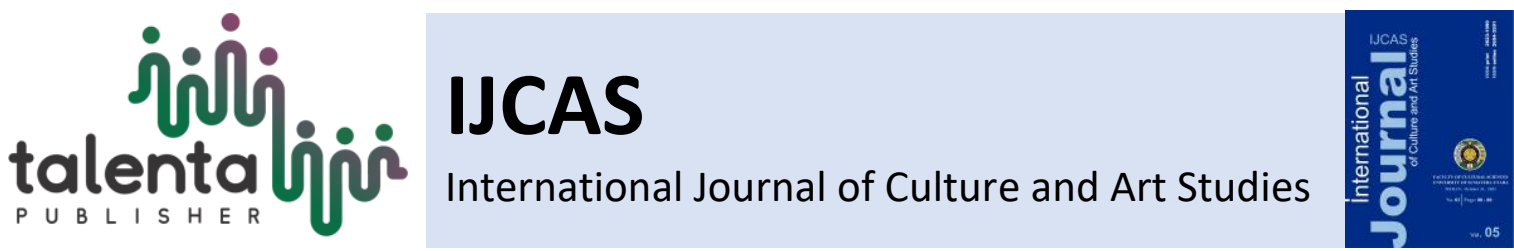

\title{
The Comparative Study of Form and the Structure of Sri Lankan Gataberā and Pahatharața Berā with the Indian Mridanga Drum
}

\author{
Isuru Dehideniya * \\ University of Visual and Performing Arts, Colombo, Sri Lanka.
}

\begin{abstract}
The Gataberā and Pahatarața berā are the main drums in two regions in Sri Lanka; also the Mridanga is one of all South Indian main drums. This research is a comparative analysis of the similarities and differences of form and structure between those Indians and Sri Lankans drums. That is conducted in the qualitative method. Several similarities and differences are discovered from the form and structure between those drums under the organization, order of the elements, construct process, and shape. The final conclusions are, 1) the form of all drum heads of Gatabera, Pahatharata bera, and Mridanga is similar, and also that form represents an Indian subcontinent drum head variety, but their structure is different according to the culture of both countries. 2) The form and structure of Gatabera and Mridanga drum bodies are slightly similar.
\end{abstract}

Keywords: Drums making, Gațaberā, Mridanga, Pahatarața berāa, South Asian drums

Received 12 August 2021 | Revised 24 August 2021 | Accepted 26 October 2021

\section{Introduction}

The Gataberā and Pahatarața berāya are main drums in the Sri Lanka. The Gataberā traditionally has been used in Sri Lankan Up-country (Kandyan) dance and rituals, another two names called that as Kandyan Drum (Udarata Beraya) and Magul Beraya (Ramanayake, 1986, p. 2) (Disanayaka, 2018, p. 174. Suraweera has mentioned several names used for Pahatarata berāya (Low-country drum) in his theses, such as Yak Beraya, Devol beraya (named after the ritual Devol Maduva and the god devol), Ruhunu beraya (named after a historically important Sinhala kingdom of the south called Ruhunu) and Gosśaka beraya (gōśaka meaning noisy) (Suraweera, 2009, p. 50) (Ramanayake, 1986, p. 14). However, all Sri Lankan Artists have generally acknowledged that drums represent the two traditional aspects of Sri Lanka. The word "Mridangam" is derived from the two Sanskrit words "Mrid" (clay or earth) and "Ang," (body). Mridanga or Mridangam instrument used in South India, the Maddalam (Tamil, Teligu) and Maddale (Kannada) are other names of Mridangam, so also the pakhawaj is a similar instrument of Mridanga, used in North India (Deva, 1987, p. 76) (Krishnaswamy, p. 8).

\footnotetext{
*Corresponding author at: University of Visual and Performing Arts, Albert Crescent, Colombo 07, Sri Lanka. 
The name Mridanga has been mentioned in Valmiki's Ramayana, Mahabharata, and Baratha's Natya Shastra (Prapatthong, 1998, pp. 177-179). We cannot conclude the difference or similarity of present-day Mridanga and historical Mridanga. However, the present Mridanga may be a historical representation of music evolution and Indian drum structure. Because of that reason, the Mridanga drum is used for the present research among Indian drums. Today should comparative study the similarities and differences of the form and structure of Indian and Sri Lankan drums. The research problem is the similarities and differences of the form and structure of those Indian and Sri Lankan Drums.

\section{Method}

This comparative study has been conducted in the qualitative method. In the process of comparative study can be analyzed and compared, two or more objects or ideas. Also, a comparative study shows how two subjects are similar or show how two subjects are different (Bukhari, 2011). Firstly, the data collected regarding the makes process of Indian and Sri Lankan drums. In there, they used Secondary data such as books, journal articles, and videos. The primary source has been collected from the observation of the drums making process in Sri Lankan traditional drums makers' village named Kuragala in Kandy District. "The shape of something" is one of the essential meanings applicable to the form; also "the way that something is built, arranged, or organized" is an essential meaning of structure (Merriam-Webster). Usually, the drums can be divided into two parts as head and body (Dennis, 2006, p. 7). Those two parts construct the whole form and structure of the drum. So secondly, should be comparative analyzed the similarities and differences of form and structure between those Indians and Sri Lankans drums. That has driven under the sub-questions of the way those drums have been built, the order of the elements, how is organized, and what is the shapes. 


\section{Results and Discussion}

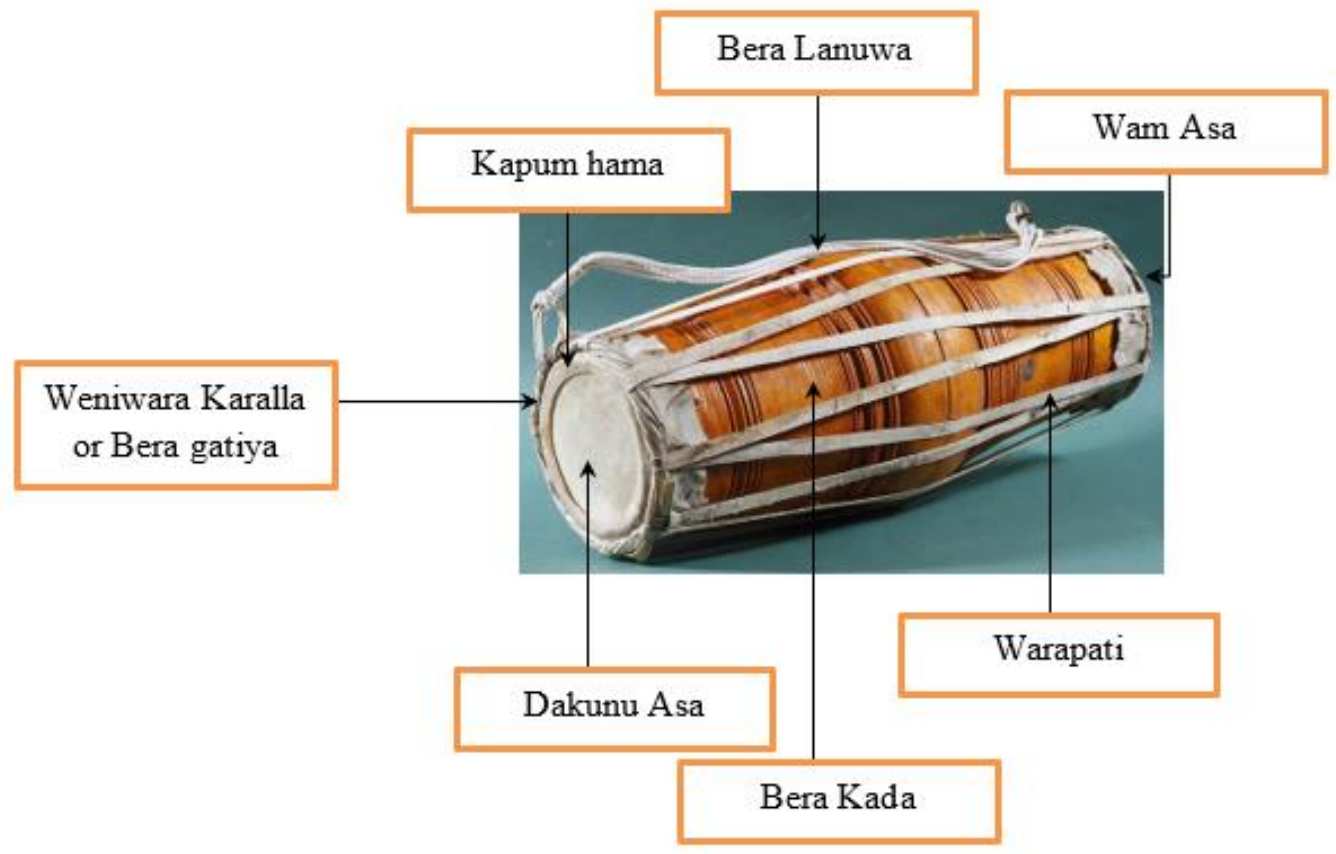

Figure 1. The parts of Gatabera

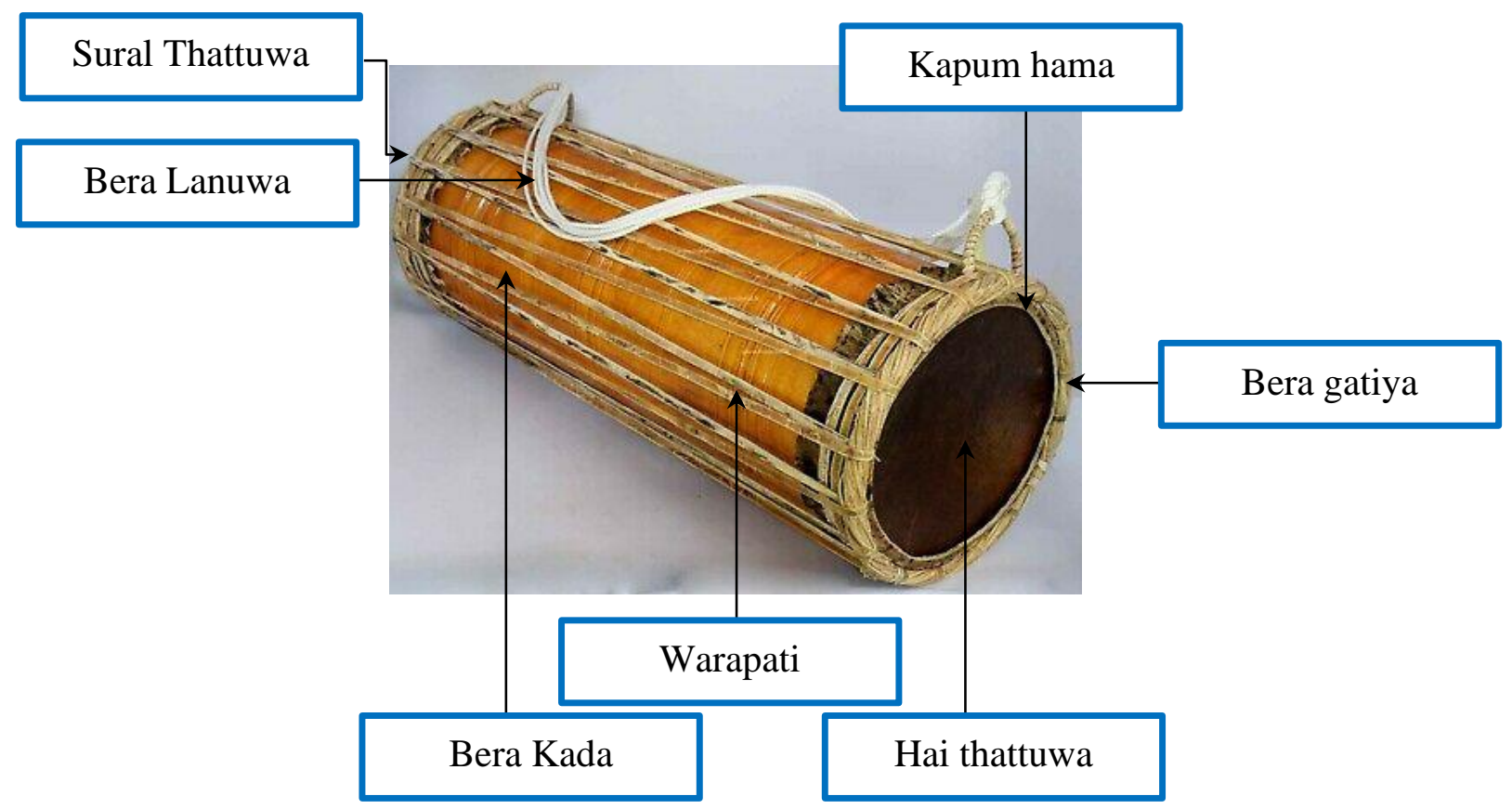

Figure 2. The parts of Pahatharata bera (Low-country drum)

The definitions of the Pahatharata bera and Gatabera drums elements. Some meanings are referenced from Suraweera (Suraweera, 2009, p. 51).

- Wam Asa- Left inner skin.

- Dakunu Asa- Right inner skin.

- Hai thattuwa- the thicker drumhead. 
- Sural thattuwa - thinner drumhead.

- Bera lanuwa - the waist strap.

- Bera kada - the shell of the drum.

- Kapum hama- the outer skin.

- Warapati - the straps that connect the two drum heads along the drum.

- Bera gatiya (weniwara karalla) - the woven ring around the edge of the drumhead (Drum rim or ring).

\subsection{The body of Gatabera and Pahatharata bera}

The Gatabera belongs to Compound Conical shaped, as well as the body may be made timbers such as Golden shower, ironwood, Thespesia populnea, Deodar cedar, Margosa, and Jackwood (Disanayaka, 2018, p. 175). The Low-country drum body is cylindrical-shaped and made from the Golden shower, Vitex altissima, Margosa, Jackwood, Coconut, and Caryota urens (Suraweera, 2009, p. 50). The traditional Low-country and Gatabera drum makers are measured from the "Viyat and Angul" system; a viyat is the length from the thumb to the little finger, as the fingers are spread. An angul is the length from the first joint above the palm to the end of the index finger. Their traditional acceptance was three viyat and three angul in length, and one viyat at the diameter of the drumhead; this measure should be taken from the drummers' hands (Suraweera, 2009, pp. 52-53). That method represents the correlation of drum player (drummer) and instrument because traditional makers focused on the physical capacity of those things and got the maximum benefit. However, this method does not use in the present commercial productions. The drum makers of different states in Sri Lanka, get to the measurements approximate 27 to 29 inches for Gatabera drums length. The diameter of the Gatabera drum head is 8 inches (Suraweera, 2009, p. 45) (Disanayaka, 2018, p. 175) (Ramanayake, 1986, p. 3); approximate 27 inches for Low-country drums length and diameter of the drumhead is around 7.5 to 9 inches (Suraweera, 2009, p. 50).

\subsection{The Gatabera and Pahatharata bera head.}

The form and structure of Gatabera and Low-country drum heads are similar, but different animal skins are used. Cow skin is used to cover the Gatabera left head, and monkey skin uses to cover the right head (Ramanayake, 1986, p. 3); however, in the present-day, monkey skins are very rare and instead use goat skins for the right side (Suraweera, 2009, p. 44). Both heads of the Lowcountry drum are covered from the cow's stomach (Ramanayake, 1986, p. 15) (Suraweera, 2009, p. 56). Those Sri Lankan drum heads have two parts as traditionally; the first part is Bera thattuwa or Bera asa, the second part is Bera hakma or Kapum hama. The Bera asa or Bera thattuwa is 
the basic skin and playing skin of Gata bera and Low-country drums. Before, attaching the Bera asa to the drum, a rim named Gatiwala (made of bamboo or vines) fixes like circular to the drum shell of Gatabera and Low-country (Figure 03). After that, Bera asa soaks in water and puts it to the top of the drum hole, and string is used to tightly bind Bera asa with Gatiwala (Figure 04). The Low-country drum has used a Gatiwala for each head, but the Gatabera right face uses two Gatiwala, and the left face uses one Gatiwala. After that, Bera hakma is put on the top of Bera asa (Suraweera, 2009, pp. 60-63) (Yakkhanadha, 2020) (Suraweera, 2009, p. 58) (Figure 04). On the top of the surface in the Bera hakma of Low country and Gatabera drums are cut out in a circular shape and have left a gap of around half an inch from the edge of the drum (Suraweera, 2009, pp. 58-59). The Bera gatiya is on around the edge of Bera hakma. Around the Bera gatiya of Gatabera has eight perforations. Around the Bera gatiya of Pahatharata bera has eighteen perforations. The Warapata insert into perforations and tie together each other head from the "W" lacing method.

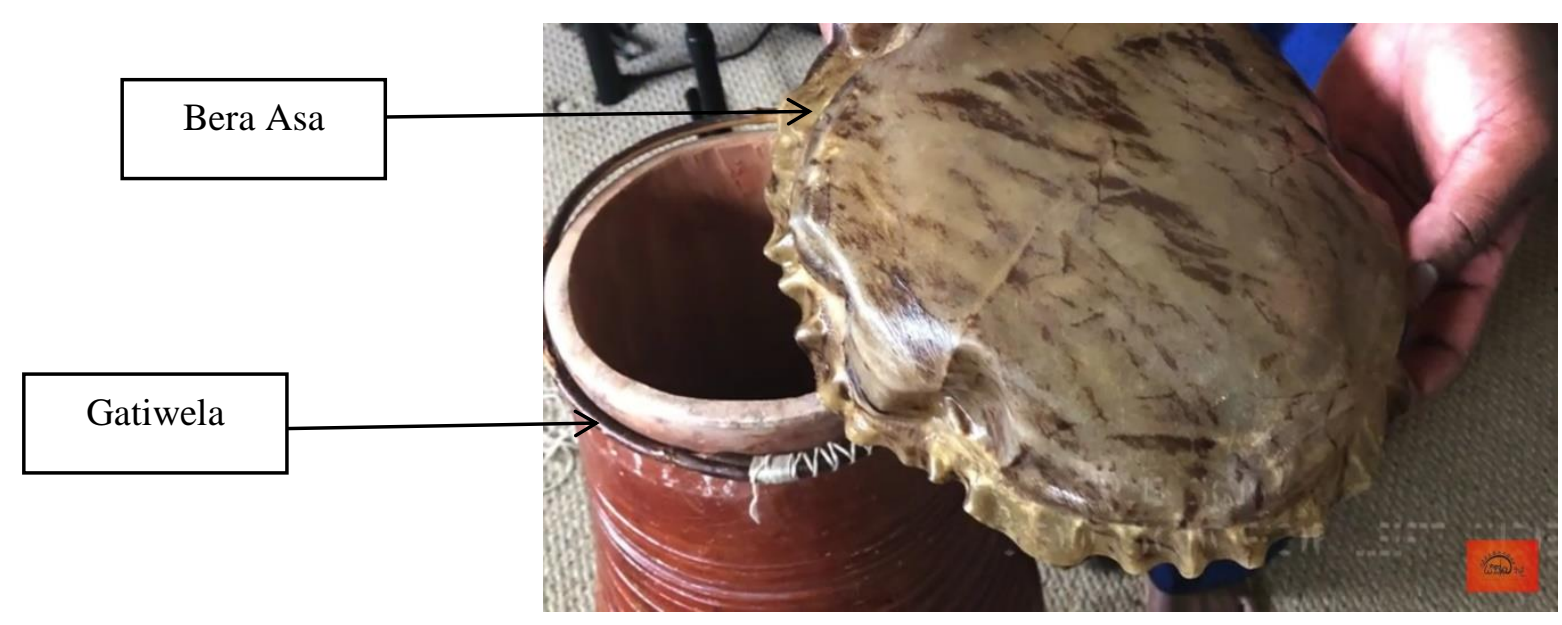

Figure 3. (Yakkhanadha, 2020)

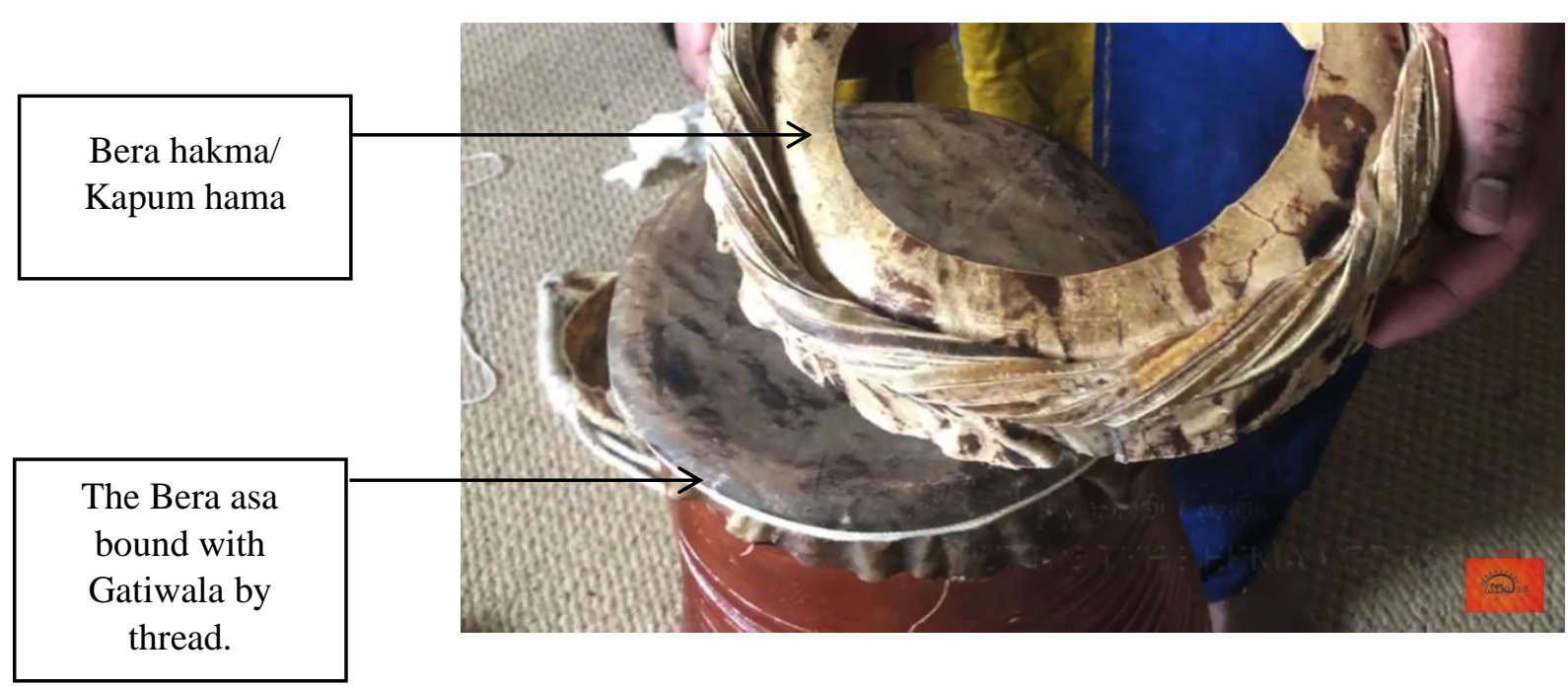

Figure 4. (Yakkhanadha, 2020) 


\subsection{Mridanga drum}

Mridanga drum belongs to the barrelled-shaped category. The Mridanga player named Esha Prasad T S has shown types of Mridanga; the below chart is referenced from his YouTube video (Prasad, 2021).

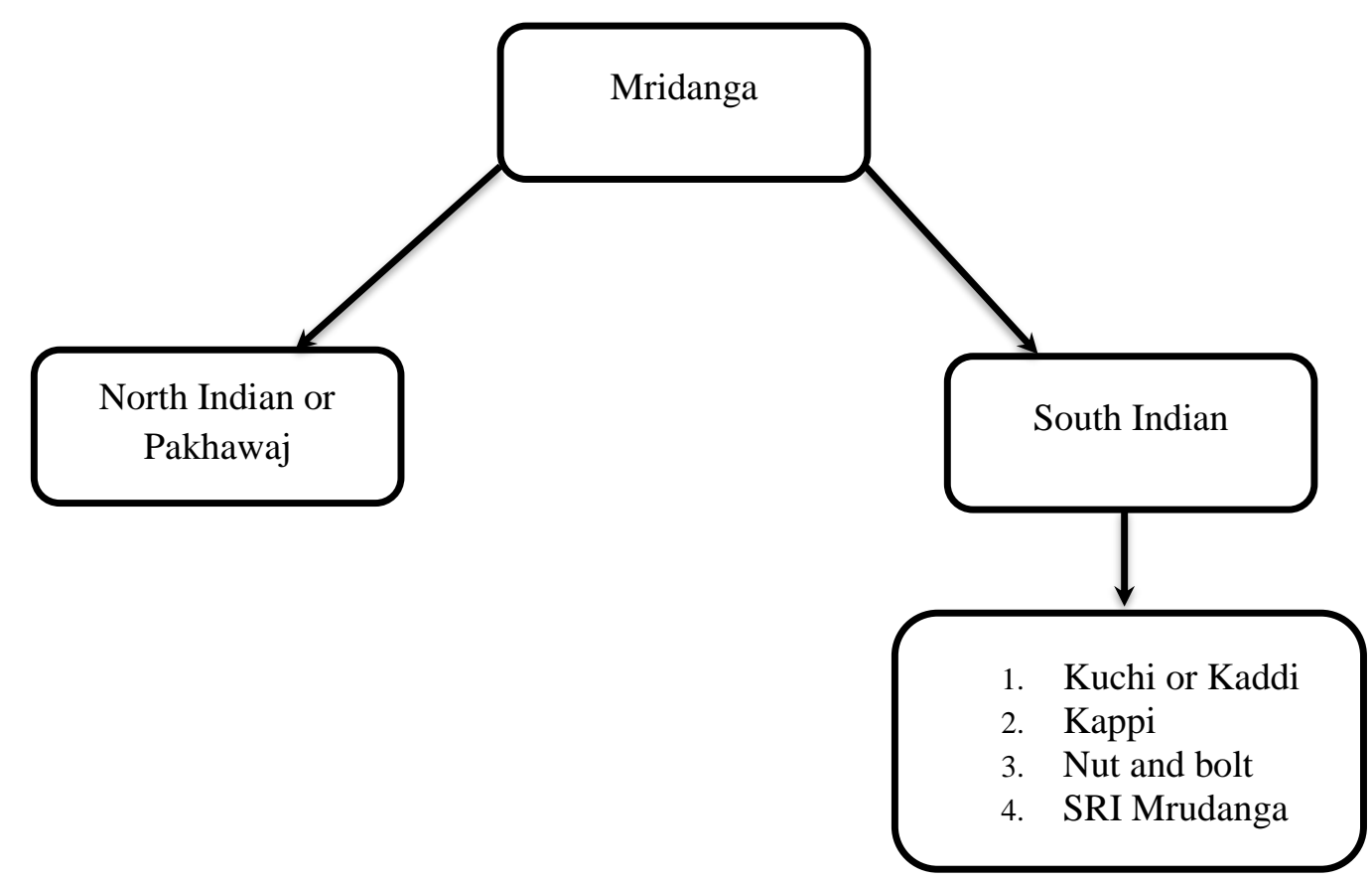

Figure 5. Types of Mridanga

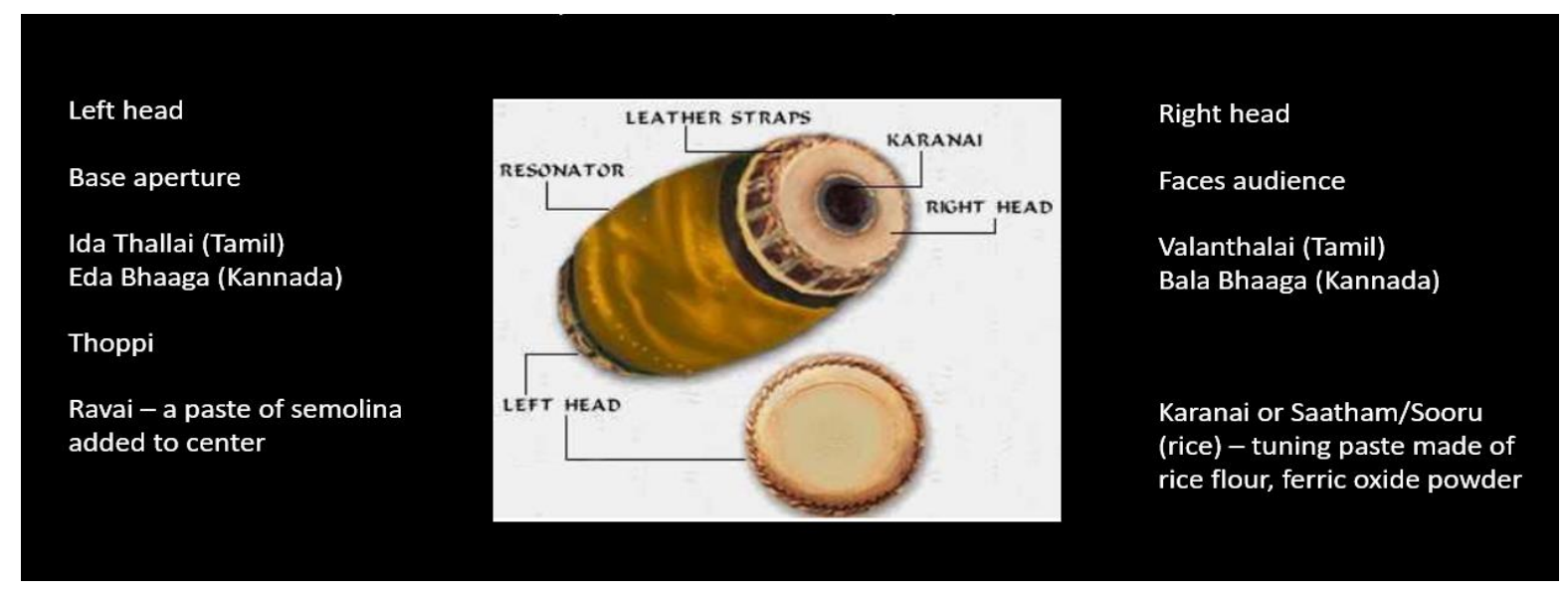

Figure 6. Parts of Mridanga (KavyaVriksha, 2020) 


\subsection{The body of Mridanga drum}

The body of Mridanga is made from Jack-wood, Redwood, Morgosa, Coconut, and Palm trees; however, Mridanga makers and players most like Jack-wood and Redwood. Mridanga is made in various sizes as one-and-a-half or two feet in length, and its diameter is twenty-five to thirty centimeters (Baral, 2017). So also, for this research, obtained the sizes from Tamil Nadu craftsmen. The Mridanga left head is bigger than the right head; a Mridanga maker Sri A Sowriyar stated three variation sizes, the first variant length is 22 inches, and the right face is 6 $1 / 4$ inches, the left face is $71 / 4$ inches, their name is Sthaayi Mridangam. The second variant length is 23 inches; the right face is $61 / 2$ inches, the left face is $71 / 2$ inches, their name is Edappaari Mridangam. The third variant length is 24 inches, and the right face is $63 / 4$ inches, the left face is 7 3/4 inches; their name is Thak Mridangam (Girish, 2019).

\subsection{The Mridanga drum heads}

The Left drum face has two buffalo pieces of leather and a she-goat leather; the she-goat leather is mounted to the below of the drum face as upside-down. The right head has three leather pieces in order from the surface into the drum shell, such as calfskin (top layer), she-goat skin (middle layer), and she-goat skin (bottom layer) (Ramamurty, 1973, pp. 29-33). The around both drum heads have strong stitched rims made in buffalo or ox leathers; those rims have sixteen perforations, leather straps inserted into those perforations, and tying both heads together to each other with the "W" lacing method. The top layer of the right face and the first two layers in the left face have removed a frame as circular-shaped. So also, an iron compound mixture named Karini has been plastered to the outer surface of the middle layer of the right face (Ramamurty, 1973, pp. 29-33). The temporary paste is plastered to the outer surface of the bottom layer of the left drum face. Usually, that paste is added to them before playing Mridanga. That paste includes soojee (fine flour), boiled rice water, and ashes (Baral, 2017).

The below discussion focuses on the Mridangam, Gäțaberaya and, Low-country drum. Additionally, it discusses several Indian and Sri Lankan drums such as pakhawaj, tabla, khol, Shudda maddalam, and tammättama, etc. Gatabera, Pahatharata bera, and Mridangam shells are different, but approx; a similar formation has on the between Gatabera and Mridangam drum shells. So also, Pahatharata bera has a cylinder shape (Dennis, 2006, p. 09); however, all those drum heads are laced by the "W" method. The insides of Gatabera and Low-country drums are rough, carved with marks, and not smooth. However, the inside of Mridanga drum is slightly smoothed rather than the Sri Lankan drums. 
BARREL DRUMS

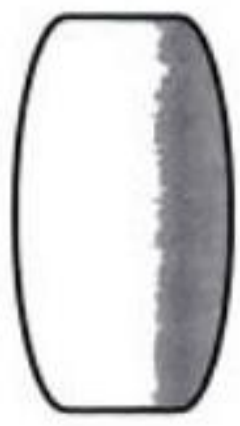

Barrel

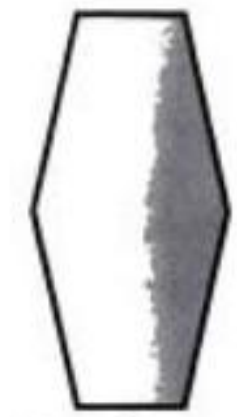

Barrel or Compound Conical
CYLINDER DRUMS
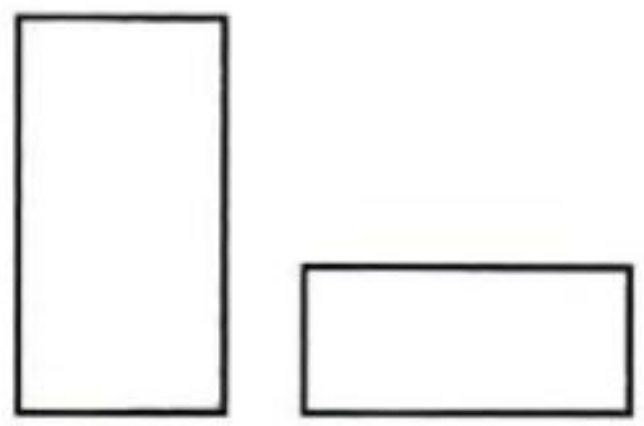

Figure 7. Barrel Drums (Dennis, 2006, p. 09)

Figure 8. Cylinder Drums (Dennis, 2006, p. 09)

Scholar Eshantha Peiris was given valuable comparative descriptions about those drums in his dissertation (Doctor of philosophy); he has put considerable effort into looking at it from a new perspective. Those descriptions should be discussed one by one.

"Regardless of the type of skins used, what distinguishes the gäta beraya from other South Asian drums is that it uses skins of a different animal on either end, making the strokes producible from each side of the drum significantly different in tone and pitch, even though the two drum heads are almost the same size." (Peiris, 2020, p. 35)

That reference is verity; both Gatabera holes are similar-sized, and different animal leathers cover the holes. But, significantly different tonal characterize are generated from each side of the drum; the main reason for this is the different thickness of the buffalo and goat leathers and tanning methods, etc. So also, both drum heads of Low-country drum are similar sized and covered with the cow stomach skins (cow stomach skins are used to both heads), but the distinguished different tonal characterize is generated; the reason for this is a slight difference in thickness of both drum head skins and playing techniques (Suraweera, 2009, xiii, 51, 70-71).

"As with many of the hand-played drums (as opposed to drums played with sticks) found in India - e.g., the pakhawaj, tabla, Mridangam, khol, and shudda maddalam - the drums used in upcountry and low-country Sinhalese rituals (gäta beraya and pahatarața beraya) feature two skins on each drum-head, with the outer skin cut out in the middle to reveal the main inner skin. Both skins on a particular side are woven together with leather strips that form a rope-like drum rim. One unique physical/acoustical feature of the gäta beraya drum - which it shares with another up-country drum, the tammätțama - is that the outer skin (käpum hama or häkma) is stiff, and affixed in a way that leaves it slightly raised above the inner skin." (Peiris, 2020, pp. 36-37)

He has pointed out similarities between the drum heads in Sri Lankan drums (Gäta beraya and low-country drum) and Indian drums (pakhavaj, tabla, Mridangam, khol, and shudda maddalam). We can name their form as a drum head variant in the Indian subcontinent (Figure 09) because 
that form is in a significant number of drum heads in the Indian subcontinent (e.g. - pakhawaj, tabla, Mridangam, khol, shudda maddalam, Thammatama, Gäta beraya, and low-country drum). Those drum heads have been constructed with three or more animal skins in India and two animal skins in Sri Lanka under different measurements and tannery methods.

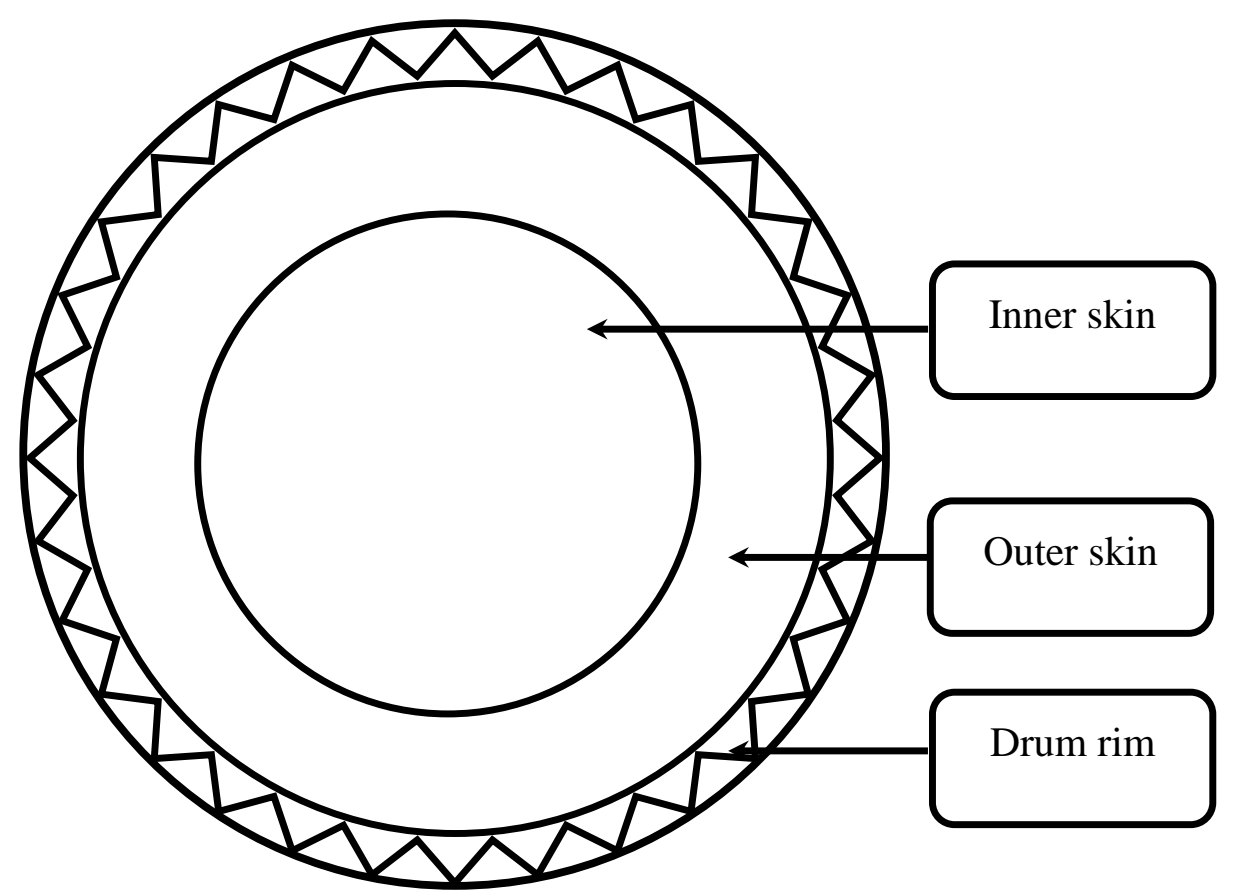

Figure 09. A drum head variant in the Indian subcontinent

The inner and outer skins of Mridanga heads should be stitched to each other by strips before they fit to the drum hole; as a result, they are also touched and cannot separate each skin (that method is in the drum faces of tabla, phakavaj and khol). In a completely different way, the skins of the Sri Lankan Gatabera and Pahatharata drum heads are fitted to the drum hole. Firstly, the Gatiwela rim is fitted to the hole of the drum shell, and the inner skin (playing skin) binds with it. Secondly, the outer skin (bera hakma) is put on the inner skin. Accordingly, the inner skin and outer skin of Gatabera and Pahatharata bera fitted to drum shells separately from each other, and not like Mridangam. Between inner and outer skins of the right head in Mridanga has inserted Kuchi/ Kaddi or Kappi. Kuchi are small sticks, and Kappi is small stones; they generate the best resonance (Girish, 2019). A thread inserts between the inner and outer skins around Tabla right head like Mridangam. But the Gatabera outer skins (Kapum hama), in a way, have been left slightly raised from the inner skin (approximately $1-1.5 \mathrm{~cm}$ ) as slightly curve-shaped, thus have not touched the inner and outer skins of Gatabera drum head (Figure 10). This pattern is also on the right head in the Thammattama drum of Sri Lanka. In there, Gatabera and Thammattam makers used rolled papers and inserted to the between of inner and outer skins as well as and drying with the breeze at the end of the drums making process. As a result, those outer skins have slightly risen from the inner skin (Figure 10). Two different mixtures paste to both inner skins of 
Mridanga drum heads, that point can be seen on many Indian drums, but Gatabera and Pahatharata bera are not like that.

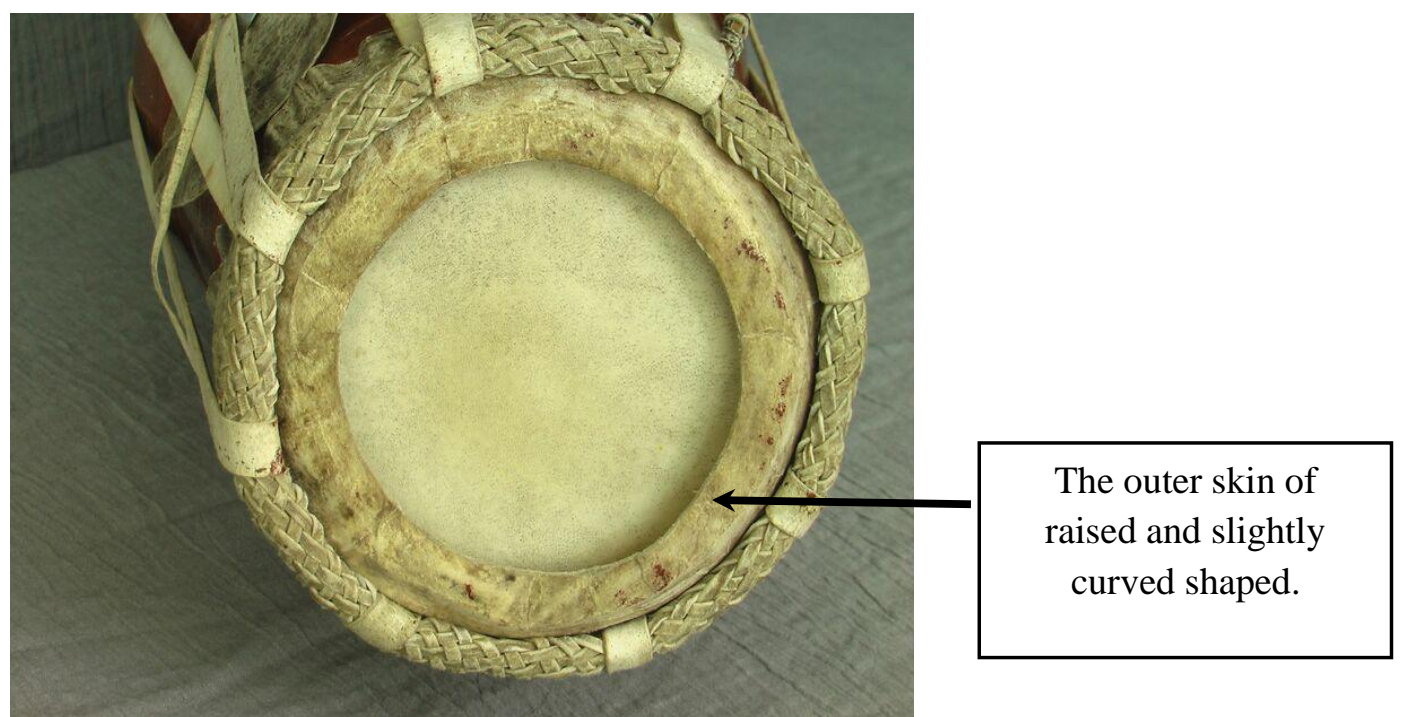

Figure 10. Gatabera head

Those drums tuning and play postures are different. Usually, the Mridangam is tuned to a musical note before the playing; the players use a special stone to strike the rim. The Gatabera drum and Low-country drum do not tune to any special musical note as traditionally. Sometimes the Mridangam players insert the metal rings or wood pieces between lace and drum shell for tune adjusting the drum, but those Sri Lankan drums are not like that. However, the Gatabera players use for sound adjusting a special rod named Bera ula, Bera polla, Beraliiya. The traditional Mridangam players are sitting and also playing Mridangam drum is positioned in the player's lap. However, Gatabera and Low-country drummers stand and play while their drums are tied to players' hips.

\section{Conclusion}

Between Gatabera (compound conical-shaped) and Mridangam (barrel-shaped), shells have a slightly similar shape, but the Pahatharata bera (cylinder-shaped) is different from the shell shapes of the other two. All drums have two holes open ends over, Gatabera and Low-country drum's both holes sizes are the same with each other but Mridanga both holes sizes are different. However, those Sri Lankan drums produce distinguished tonal characteristics from either head because of different skin thicknesses and playing techniques. So also, both drum heads of those drums are tied with each other by the "W" lace method to the body of the drum. For that, numbers of perforations are found around the leather rims of the drum head. The most important point is the form of those drums heads, represented in a drum head variant in the Indian subcontinent. Especially, this form is used in a significant number of drum heads among Indian subcontinent 
drums. In there, Mridanga has used three or more skins for inner and outer and attached to each one and cannot be separated; as a result, inner and outer skins are touched together. Rather than that, a different method is used in Sri Lanka. Two skins are used to inner and outer of Gatabera and Low-country drum heads; also, their inner and outer skins are fitted to drum shells separately from each one; those skins do not touch each other. However, a mixture is pasted to the Mridanga inner skin, but that Sri Lankan drums are not like that. Traditionally, Sri Lankan drummers play with stand posture, and Mridanga players play with sit posture. Mridanga drums tuning to musical notes, but those Sri Lankan drums do not like that. Accordingly, the final conclusions are, 1) the form of all drum heads of Gatabera, Pahatharata bera, and Mridanga is similar, and also that form represents an Indian subcontinent drum head variety, but their structure is different according to the culture of both countries. 2) The form and structure of Gatabera and Mridanga drum bodies are slightly similar.

\section{REFERENCES}

[1] Baral, B. (2017). Making of Mridangam. Retrieved 05 30, 2021, from D'source: http://www.dsource.in/resource/making-Mridangam-instrument-bengalurukarnataka/making-process

[2] Bukhari, S. A. H. (2011). What is comparative study. Available at SSRN 1962328. http://dx.doi.org/10.2139/ssrn.1962328

[3] Dennis, W. (2006). Making Drums. Newyork: Sterling Publishing Company.

[4] Deva, B. C. (1987). Musical Instruments of India. Delhi: Munsiram Manoharlal Publishes.

[5] Disanayaka, D. M. (2018). Sampradika Gatabera Nirmaana Thaakshanaya Pilibadhawa Wimasumak. URSARU, 01.

[6] Gata bera. (n.d.). Retrieved 08 13, 2021, from Grinnell College Musical Instrument Collection: https://omeka-s.grinnell.edu/s/MusicalInstruments/item/1524

[7] Girish, V. (2019, 04 13). The Making of the Mridangam - A Documentary Film. Retrieved 06 15, 2021, from You Tube: $\mathrm{https}: / / \mathrm{www}$. youtube.com/watch? $\mathrm{v}=1 \mathrm{rGgllzIgic} \& \mathrm{t}=308 \mathrm{~s}$

[8] Kandyan Art Association. (2012, 05). Geta beraya. Retrieved 08 13, 2021, from flickr: https://www.flickr.com/photos/kandyan_art_association/7411388104/in/poolhanddrumming/

[9] KavyaVriksha. (2020, 04 23). Evolution and Fundamentals of Mridangam Percussion Accompaniment. Retrieved 05 22, 2021, from KavyaVriksha: https://medium.com/kavyavriksha/evolution-and-fundamentals-of-Mridangampercussion-accompaniment-9a4d63cc6ac0

[10] Krishmaswamy, S. (1965). Musical Instruments of India. Ministry of Information and Broadcasting Goverment of india.

[11] Merriam-Webster. (n.d.). Form. In Merriam-Webster.com dictionary. Retrieved October 23, 2021, from https://www.merriam-webster.com/dictionary/form

[12] Merriam-Webster. (n.d.). Structure. In Merriam-Webster.com dictionary. Retrieved October 23, 2021, from https://www.merriam-webster.com/dictionary/structure

[13] Peiris, E. (2020). The Gäta Beraya Drumming Tradition Of Sri Lanka. [Doctor of Philosophy, University of British Columbia]. University of British Columbia. https://dx.doi.org/10.14288/1.0394161 
[14] Prapatthong, S. (1998). Thai Musical Instruments Based on Archaeological and Other Related Source from The Ancient to Medieval Period In Indian Context. [Doctor of Philosophy, Maharaja Sayajirao University of Baroda]. Shodhganga: a reservoir of Indian Theses. http://hdl.handle.net/10603/72143

[15] Prasad, T. S. (2021, Feb 26). Types of MRIDANGAM : Traditional Mrudanga, SRI Mrudanga and much more. Retrieved 06 15, 2021, from You Tube: https://www.youtube.com/watch?v=tBJHkRG-j9o

[16] Ramamurty, D. (1973). The theory and practice of Mridanga. Rajahmundry, india: Saraswathi power press.

[17] Ramanayake, U. B. (1986). Sinhalese Traditional Art of Drums. Vidyodaya Journal, 14(1).

[18] Suraweera, S. (2009). Sri Lankan, Low-Country, Ritual Drumming: The Raigama Tradition [Doctor of Philosophy, University of Canterbury]. University of Canterbury Repository. http://dx.doi.org/10.26021/5167

[19] Traditional Drum 5 - Yak Bera. (n.d.). Retrieved 08 13, 2021, from pinterest: https://www.pinterest.com/pin/552676185505110249/

[20] Yakkhanadha. (2020, 02 12). kandyan drum head changing. Retrieved 06 15, 2021, from You Tube: https://www.youtube.com/watch?v=A5vBX_a75qU 